\title{
Release of Cortical Catecholamines by Visual Stimulation Requires Activity in Thalamocortical Afferents of Monkey and Cat
}

\author{
Richard T. Marrocco, Ross F. Lane, ${ }^{a}$ John W. McClurkin, Charles D. Blaha, ${ }^{\mathrm{b}}$ and Michael F. Alkire \\ Institute of Neuroscience, University of Oregon, Eugene, Oregon 97403
}

\begin{abstract}
Catecholamine (CA) release was measured in vivo in the monkey and cat visual cortices electrochemically. Stereatemodified, graphite-paste electrodes were used to monitor changes in norepinephrine and dopamine release. Micromolar changes in CA concentration were obtained by stimulation of the eye with nonspecific (strobe) or specific (oriented bars, radial gratings) stimuli. CA release depended on which eye was illuminated. Electrodes passed tangentially through the striate area recorded release following visual stimulation of one eye or the other in succession, and the shift in eye dominance occurred at about $500 \mu \mathrm{m}$ intervals. The magnitude of CA release was highly correlated with the ocular dominance of neuronal activity measured with tungsten microelectrodes. Light-stimulated release was not recorded in monkey area V2, V4, or somatosensory area 1 , but was recorded in cat V2, suggesting that the presence of LGN afferents is associated with CA release. Results are discussed in terms of the role of geniculate activity and the specific role of CAs in cortical information processing.
\end{abstract}

Several monoaminergic neurotransmitters, including norepinephrine (NE) and 5-HT have been identified by histofluorescence or immunohistochemistry in the visual cortex of primates. Although the monoamines are found in all cortical areas, there are marked regional differences in tissue concentration (Brown et al., 1979; Levitt et al., 1984; Morrison and Foote, 1986). Additionally, the monoamines are not homogeneously distributed across laminae within the striate cortex. 5-HT is most concentrated in lamina 4 , while catecholamine (CA) concentrations are highest in laminae 3, 5, and 6 (Morrison et al., 1982; Kossofsky et al., 1984; Levitt et al., 1984). Dopamine (DA), while present in most neocortical regions, exists only in relatively low (Levilt et al., 1984) or trace anounts (Brown et al., 1979 ) in the striate area. Immunohistochemical studies suggest that NE and 5-HT are not found within any intrinsic class of cortical neuron. Rather, they are contained in terminals whose somata are primarily within the brain-stem locus coeruleus (LC)

Received Aug. 26, 1986; revised Feb. 27, 1987; accepted Mar. 3, 1987.

This research has been supported by PHS Grants NS 13556, 5T32 MH 17148 NSF Grant 82-07531, and grants from the Oregon Medical Research Foundation and the Office of Research Services, University of Oregon. We thank P. Trombley for performing the high-performance liquid chromatography assay and B. Gordon for helpful comments on the manuscript.

Correspondence should be addressed to Richard T. Marrocco at the above address.

a Present address: Departments of Chemistry and Psychiatry, University of British Columbia, Vancouver, British Columbia V6T 1Y6, Canada.

Present address: Department of Psychology, University of British Columbia, Vancouver, British Columbia V6T 1Y6, Canada.

Copyright (C) 1987 Society for Neuroscience $0270-6474 / 87 / 092756-12 \$ 02.00 / 0$ and raphe nuclei, respectively (e.g., Levitt and Moore, 1978; Itakura et al., 1981).

Recent research has focused on the role of the CAs in the development of binocular vision. Kasamatsu and colleagues (Kasamatsu and Pettigrew, 1979; Itakura et al., 1981; Kasamatsu and Heggelund, 1982) have argued that NE may maintain the binocularity of neurons in kitten striate cortex following monocular deprivation. The conclusions from these studies have been called into question by several laboratories (e.g., Daw et al., 1984; Adrien et al., 1985; Trombley et al., 1986).

The role of CAs in the adult brain has also been investigated. NE has been shown to alter the shapes of action potentials in hippocampal pyramidal cells (Pocket, 1985) and alters the effective signal-to-noise ratio of responses of neurons to afferent inputs (Kasamatsu and Heggelund, 1982; Videen et al., 1984). Recently, McClurkin et al. (1985) demonstrated that visual stimulation temporarily increases the concentration of $\mathrm{NE}$ in the extracellular fluid (ECF) in monkey striate cortex. The role of NE as a transmitter in the adult monkey visual system, however, is not clear. While some of the actions of NE may be due to increased intracellular levels of cAMP that result from stimulation of membrane-bound adenyl cyclase (Bloom, 1975), the role of $\mathrm{NE}$ in shaping responses of specific cell types to receptive field stimuli and in information processing in general is unknown.

The objective of the present study was to determine the role of CA transmitter release in cortical neuronal circuits whose physiological properties and role in visual processing are well established. Using standard electrophysiological techniques for extracellular recording and in vivo electrochemical techniques for measurement of CA release, we have examined the visually evoked responses of the monkey striate cortex (area V1). Two questions are addressed in this paper: (1) May CAs be released with any visual inpul or is patterned visual stimulation more effective? (2) If the release can be evoked by any stimulus, is only one eye effective or are both effective? If monocular, the cortical release measured in the middle laminae is probably mediated by monocular pathways through the lateral geniculate nucleus (LGN; e.g., Wiesel and Hubel, 1966). If so, an electrode passed tangentially through the granular laminae of $\mathrm{Vl}$ ought to record release from sites dominated alternately by one eye or the other. Similar but smaller effects could be detected in cortical laminae 2 and 3 as a result of inputs from LGN interlaminar neurons (e.g., Hubel and Wiesel, 1972; Weber et al., 1983) or perhaps nonoriented neurons (Livingstone and Hubel, 1984). If $\mathrm{NE}$ is detected following visual stimulation of either eye, release may be mediated by pathways through the LC (e.g., Aston-Jones and Bloom, 1981) or pulvinar (Bender, 1982; McClurkin, 1984) or by binocular cortical neurons. A brief re- 
port of these results has appeared elsewhere (McClurkin et al., 1985).

\section{Materials and Methods}

Animals and surgery. Experiments were performed on 5 adult cynomolgus macaque monkeys and seven adult domestic cats. The care and use of animals in this project conformed to the guidelines of the American Physiological Society and the National Institutes of Health. The methods for surgical implantation were identical to those described previously (McClurkin and Marrocco, 1984). Briefly, stainless steel wells for insertion of electrodes and anchoring bolts for atraumatic head immobilization were cemented to the skulls of animals deeply anesthetized with Nembutal $(35 \mathrm{mg} / \mathrm{kg})$. The scalp was resewn around the wells, and the animals were allowed to recover from the anesthesia. Prophylactic doses of Gentocin and dexamethasone were given to prevent infection and speed wound healing, respectively. The animal's diet of lab chow was supplemented with fresh fruit (monkeys) or meat (cats) during this period as well. Seven to $10 \mathrm{~d}$ recovery was allowed for all animals, and frequent checks of body weight, activity levels, and food/water consumption were made before any recording sessions were begun.

Special care was taken to prevent animal discomfort during the postoperative period. Immediately after surgery, animals were placed in a cushioned, humidified incubator at $80^{\circ} \mathrm{F}$. As soon as major muscle activity returned, animals were given an i.m. injection of Talwin (10 $\mathrm{mg} / \mathrm{kg}$ ) to reduce postoperative pain. The injections were repeated every $6 \mathrm{hr}$ for $2 \mathrm{~d}$.

Visual stimulation. Several types of visual displays were used. A Grass photostimulator was used for stroboscopic flashes. Intensity and rate were independently controllable. Intensity was also varied by placing the strobe at several distances from the animal. The radial grating stimulus was presented on a tangent screen $1.14 \mathrm{~m}$ from the animal's corneas. At this distance, $1 \mathrm{~cm}$ was equal to $0.5^{\circ}$ arc of visual angle. The grating was drawn in ink on acetate transparencies and projected onto the tangent screen with a specially constructed overhead projector. The space-averaged luminance of the grating was $14.3 \mathrm{~cd} / \mathrm{m}^{2}$ (light bars, 8.2 $\mathrm{cd} / \mathrm{m}^{2}$; dark bars, $0.24 \mathrm{~cd} / \mathrm{m}^{2}$; contrast, $95 \%$ ). When spinning, the radial velocity was $5^{\circ}$ arc/sec. Rectangular light bars of variable dimensions were drawn on acetate sheets and presented with the overhead projector. Linear stimulus motion was produced by supplying voltage ramps to a mirror galvanometer placed in the overhead projection beam. Other details of our preparation have been reported elsewhere (McClurkin and Marrocco, 1984; Marrocco and McClurkin, 1985).

Electrophysiological methods. For recording sessions, animals were premedicated with atropine sulfate and anesthetized with Ketamine (10 $\mathrm{mg} / \mathrm{kg}$ ). The trachea was sprayed with Cetacaine and an endotracheal tube inserted. Dexamethasone was given i.m. every $4 \mathrm{hr}$ to prevent bronchial secretions and reduce inflammation. Animals were placed on a heating pad and mounted in the head-holding device. A transcutaneous catheter was inserted into the saphenous vein. Neuromuscular blocking agents $(3.8 \mathrm{mg} / \mathrm{kg} / \mathrm{hr}$ Flaxedil; $0.7 \mathrm{mg} / \mathrm{kg} / \mathrm{hr} d$-tubocurarine) were infused i.v. in an electrolyte replacement solution through a standard hospital transcutaneous catheter. Ketamine anesthesia was terminated and replaced with a respired mixture of $70 \% \mathrm{~N}_{2} \mathrm{O}$ and $30 \% \mathrm{O}_{2}$.

It should be emphasized that no pressure points, open wounds, or tissue irritation was present during our recording sessions. No pain is produced by the immobile, transcutaneous i.v. catheter or the ECG needles. The tracheal area was reanesthetized at $4 \mathrm{hr}$ intervals with an aerosol solution of $2 \%$ lidocaine with epinephrine.

During the recording sessions, we measured EEG, ECG, body temperature, and expired $\mathrm{CO}_{2}$ and maintained these within normal physiological limits. We recorded epochs of EEG records on magnetic tape during the various stimulus conditions for off-line spectral analysis. Typically, EEG records showed a predominance of slow-wave records occasionally interrupted for $1-2$ sec periods by desynchronized activity, typical of an unstressed animal. Thus, our autonomic monitors provided good evidence of an adequately anesthetized, unstressed animal.

Standard methods for extracellular recording with tungsten microelectrodes were used (McClurkin and Marrocco, 1984). Tangential or normal penetrations through V1 were made from the opercular surface.

Each monkey was recovered at the end of each recording session and used again in other experiments. Each monkey was run at least 3 and as many as 6 times at biweekly intervals. Topical antibiotics were placed in the recording wells and vitamin B and Gentocin were given systemically. Cats were used once or twice only.

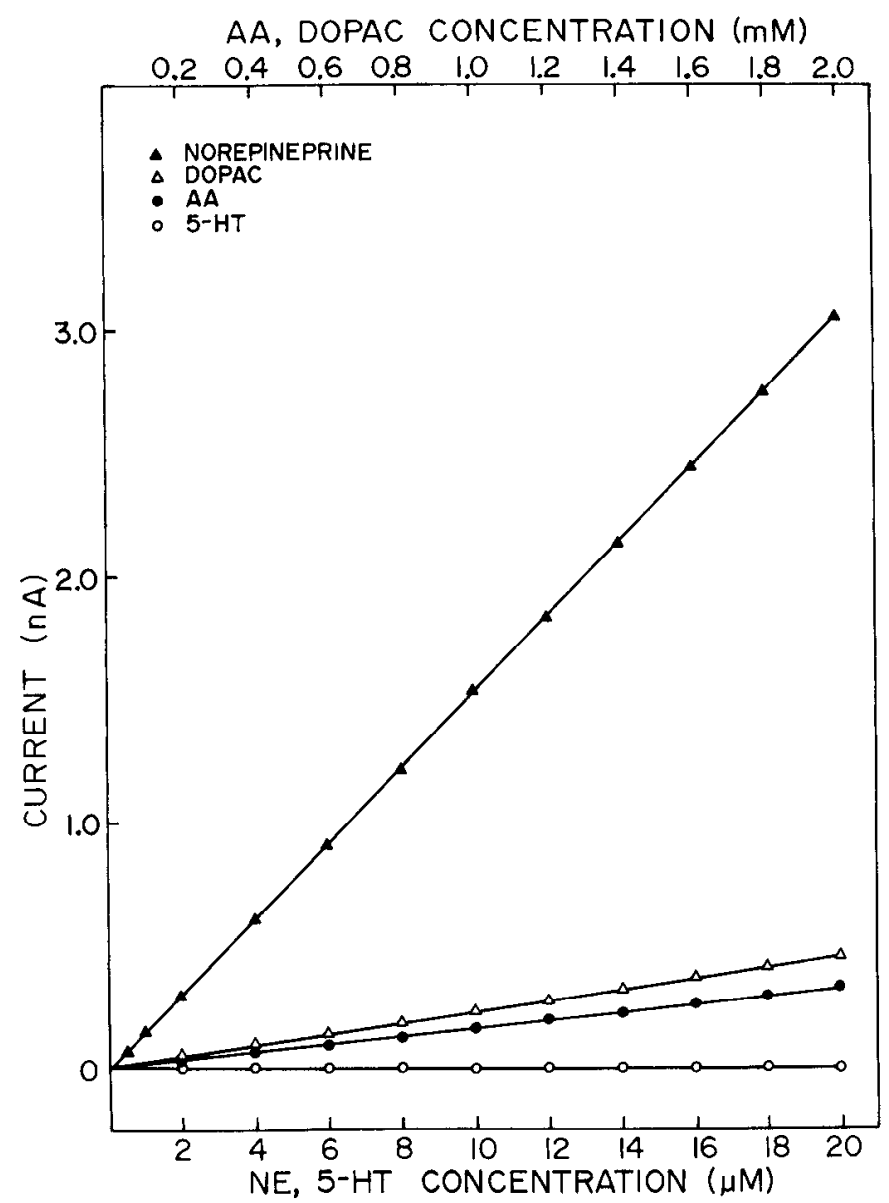

Figure 1. Oxidation currents measured for norepinephrine (NE, solid triangles), 3,4-dihydroxyphenylacetic acid (DOPAC, open triangles), ascorbic acid (AA, solid circles), and 5-HT (open circles) with stereatemodified, graphite-paste electrodes. Chronoamperometric measurements were made after experimental use in $0.1 \mathrm{M} \mathrm{PBS} \mathrm{(pH} \mathrm{7.4).} \mathrm{Potential}$ step: -0.10 to $0.25 \mathrm{~V}$ versus $\mathrm{Ag} / \mathrm{AgCl}$ reference.

Electrochemical methods. The electrochemical working (recording) electrodes used in these experiments were stereate-modified graphitepaste electrodes with tip diameters of $175 \mu \mathrm{m}$. These electrodes were constructed, calibrated, and characterized as previously described (Blaha and Lane, 1983, 1984; Lane and Blaha, 1986). Wc have previously shown that in rat brain these electrodes allow changes in CA release to be monitored in vivo without interference from changes due to $\mathrm{CA}$ metabolites, 5-HT and its metabolites, ascorbic acid, uric acid, and other oxidizable compounds present in brain ECF (Blaha and Lane, 1983, 1984; Lane and Blaha, 1986). While these electrodes do not differentiate between NE and DA, DA is found in very low concentrations in monkey visual cortex (Brown et al., 1979; Palkovits, 1979). Therefore, DA oxidation should provide only a minor contribution to the monitored electrochemical signal. We have shown previously that the DA contribution to electrochemically monitored changes in extracellular NE concentrations in rat cerebral cortex is negligible (HowardButcher et al., 1985). In cats, NE tissue concentrations are about 2.5 times those of DA (Trombley et al., 1986).

All calibrations werc performed after experimental use at room temperature using solutions prepared with 0.1 м PBS (pH 7.4). Electrodes used for experimentation showed excellent linearity over a NE and DA concentration range from 0.5 to $20 \mu \mathrm{M}$ (see Fig. 1); calibrations were performed in solutions containing a fixed $300 \mu \mathrm{M}$ level of ascorbic acid to mimic brain extracellular fluid (Schenk et al., 1982). All electrodes used for experimentation had a selectivity for NE vs ascorbic acid of 975:1 or greater (Fig. 1). A miniature $\mathrm{Ag} / \mathrm{AgCl}$ reference electrode was prepared as described previously (Lane et al., 1978) and placed in contact with the dura away from the working electrode. A 35-gauge platinum wire was used as the auxiliary electrode. 
CURRENT ( $n A)$

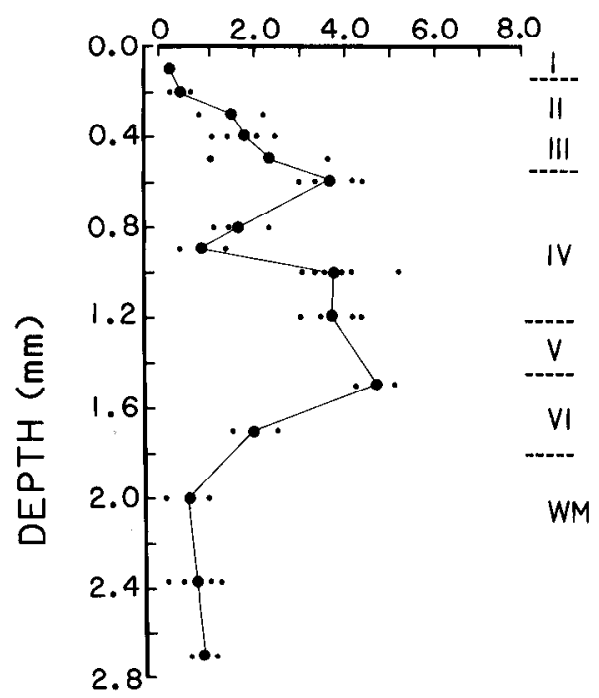

Figure 2. Mean current measured by the working electrode at various depths in area V1 from 3 monkeys (large dots). Depth measurements were obtained from microdrive readings and correlated with electrode lcsions made at the end of the penetrations. Individual observations (small dots, $n=2-6$ ) shown to either side of mean. Linear sweep voltammetry with semidifferentiation. Approximate divisions between laminae shown at right of curve. Two peaks at about $0.6 \mathrm{~mm}$ and about $1.6 \mathrm{~mm}$ were recorded in laminae II + III and VI, respectively. Baseline responses were recorded in laminae I, the III/IV border, and the optic radiations.

Electrochemical measurements were conducted with a multipurpose electrochemical circuit similar to that described clscwhere (Lanc et al., 1978,1979 ). Both linear potential sweep voltammetry (with semidifferentiation) and chronoamperometry were used. Semidifferential voltammetry was used to identify the presence and relative extracellular levels of CAs, whereas chronoamperometry was used to measure all time-dependent changes in CA release. Linear sweep voltammetry was performed by applying linear potential ramps $(-0.10$ to $+0.25 \mathrm{~V}$; scan rate, $10 \mathrm{mV} / \mathrm{sec}$ ) at $10 \mathrm{~min}$ intervals to the working electrodes and measuring the height of the CA oxidation peak current centered at +0.10 $\mathrm{V}$. Chronoamperometry was performed by applying potential pulses for $1 \mathrm{sec}$ at $1 \mathrm{~min}$ intervals from -0.10 to $+0.25 \mathrm{~V}$ vs $\mathrm{Ag} / \mathrm{AgCl}$ to the working electrodes and measuring the CA oxidation current at 1 sec. It has been demonstrated that applied potentials of $\pm 0.6 \mathrm{~V}$ or less are below the threshold required to alter neuronal excitability (Hefti and Felix, 1983). Unless noted otherwise, signals were expressed as micromolar changes from baseline, calculated using the in vitro calibration curve determined for each electrode. The principles of these methods and their application to measurements in brain tissue have been described in detail (Lane et al., 1978; Adams and Marsden, 1982; Lane and Blaha, 1986).

In practice, the graphite and tungsten electrodes were cemented together along their shafts such that the separation of the tips was about $300 \mu \mathrm{m}$. The dimensions of the ocular dominance columns in monkey cortex range from 200 to $500 \mu \mathrm{m}$ (Hubel and Wiesel, 1968), while the orientation column (i.e., a change in preferred orientation of about $15^{\circ}$ ) is about $100 \mu \mathrm{m}$ wide. This suggests that the two electrodes could be in the same or in adjacent ocular dominance columns but will usually be in different orientation columns. However, the stimulus requirements of adjacent columns are quite similar, and slight stimulus mismatches will probably only modestly underestimate CA concentrations released from the adjacent orientation column.

The present results represent sequentially obtained data, in which measurements were made with one technique while the other was disconnected. Although simultaneous measurements can be made (e.g., see Hefti and Felix, 1983), we preferred to concentrate on the stimulus conditions causing $\mathrm{CA}$ release, rather than electrophysiological re- sponses. Our experiments utilizing simultaneous electrochemical and electrophysiological recordings will be reported separately.

The oxidation currents reported here are extremely robust (changes in concentration of $2 \mu \mathrm{M}$ or more are common) and reliable. We recorded oxidation currents to visual stimulation in every animal tested. In addition, some animals tested at biweekly intervals on as many as 4 different occasions showed essentially superimposable responses to the same visual stimuli. Finally, virtually the same results as described below were obtained in each attempt at replication. Only slight variations in response amplitude were present across replications.

Using semidifferential voltammetry, we measured the endogenous levels of CAs to see how well results using our technique corresponded to previously published measurements of NE/DA terminal density as judged from fluorescently labeled terminals (e.g., Levitt et al., 1984). Figure 2 shows CA concentration (expressed as absolute current) obtained at different cortical depths. The curve shows current maxima at about $0.6 \mathrm{~mm}$ and about $1.5 \mathrm{~mm}$, in good agreement with the anatomical density of NE/DA terminals. There is also good agreement among individual observations for 3 monkeys tested. Thus, the presence of CA terminals is associated with high endogenous CA levels. Accordingly, most of the stimulus-evoked release experiments were performed at these depths.

Depletion of $N E$ and $D A$. To be certain that the graphite-paste recording electrode was sensing oxidation currents from NE and DA only, we pretreated one cat with 4 daily injections of $1.8 \mathrm{mg}$ of the CA neurotoxin 6-hydroxydopamine (6-OHDA; $7 \mathrm{mg}$ total dose). The drug was delivered through a surgically implanted intraventricular cannula following the protocol of Trombley et al. (1986). Subsequent histological examination showed the cannula to be in the third ventricle, and a black precipitate was present on the walls of the third and fourth ventricles of both hemispheres. Because the depletion protocols have not been developed, 6-OHDA was not administered to monkeys.

Following the experiment, samples of tissue from medial area 17 and a more lateral area closer to the $17 / 18$ border, weighing $150-250 \mathrm{mg}$ each, were taken from each hemisphere. Tissue levels of NE and DA were measured by high-performance liquid chromatography with electrochemical detection (Trombley et al., 1986).

Histology. Following electrophysiological measurements, small electrolytic lesions $(7 \mu \mathrm{A}$ for $7 \mathrm{sec})$ were placed at points of interest and at the end of each track to help in subsequent identification of cortical laminae and determination of shrinkage. Lesions made up to 6 weeks prior to perfusion were recovered histologically in Nissl-stained material. Following electrochemical measurements, current was passed through the graphite-paste recording electrode, depositing minute amounts of graphite in the cortical tissue. In Nissl-stained sections viewed with the naked eye, the center of the lesion appeared as a black dot.

\section{Results}

\section{Stimulus requirements for CA release}

In order to discover the adequate stimuli for CA release, we compared the responses evoked by 3 types of stimuli: a strobe light, a radial grating with a blank $2^{\circ}$ central aperture, and oriented bars of light.

Figure $3 A$ shows the effect of varying strobe light intensity on the response amplitude. CA release began with a latency of less than $1 \mathrm{~min}$ and reached a peak concentration change of about $2 \mu \mathrm{M}$ in 6-8 min. Following stimulus offset, baseline concentrations were reestablished at intervals directly proportional to stimulus intensity. Changing light intensity also caused directly proportional changes in peak response amplitude and inversely proportional changes in latency. Figure $3 B$ compares the responses evoked by stimulation at 10 and $20 \mathrm{~Hz}$. Increasing the frequency of the strobe stimulus appeared to shorten the time to peak response but made little difference in the peak concentration achieved. These stimulus-response relationships have been observed in area $\mathrm{V} l$ of each of 2 monkeys and 2 cats tested.

To acquire more information about the nature of the stimulus requirements for NE release, we used stimuli known to be effective in modulating cortical neuron activity. A spinning radial 
A

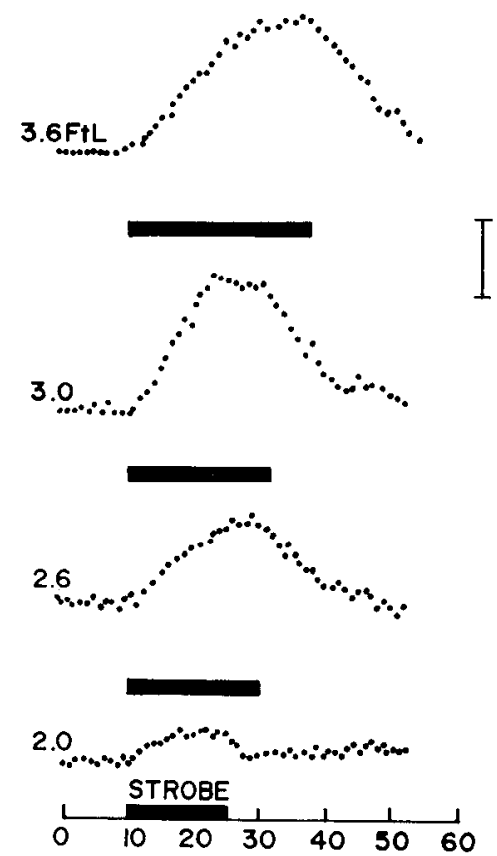

B

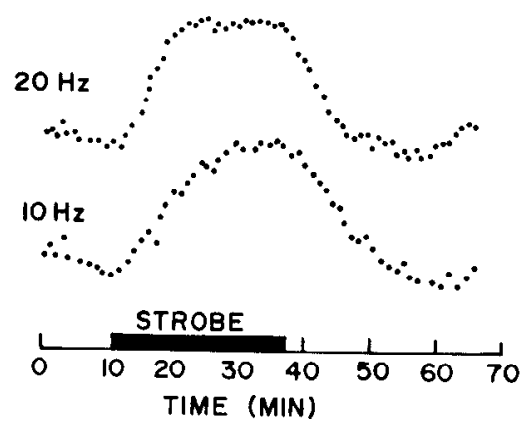

Figure 3. A, Effect of stimulus luminance on CA release recorded in lamina IV of monkey V1. Strobe stimulus, $10 \mathrm{~Hz}$. Horizontal bars beneath traces indicate stimulus duration. Increases in intensity elevate the peak response and shorten response latency. Chronoamperometric recordings. Vertical calibration bar denotes $2 \mu \mathrm{M}$ change in CA concentration. $B$, Effects of strobe frequency on $C A$ release. Increasing frequency shortens latency to peak but does not affect peak amplitude. Binocular stimulation. Recording conditions as in $A$.

grating provides moving contours with multiple orientations, useful for stimulating cortical neurons (Marrocco and McClurkin, 1985, and in preparation). In the present experiments, the tungsten electrode was used to localize the receptive field positions of multiunit activity adjacent to the graphite-paste electrode. We then centered the radial grating on these field positions such that the inside diameter of the blank central aperture lay beyond the receptive field borders. Thus, the vanes of the grating did not directly stimulate the receptive fields. Responses to the steady grating and to the grating spinning radially at $5^{\circ} \mathrm{arc} / \mathrm{sec}$ were measured. Under similar conditions the spinning, but not the stationary, grating induced cortical activity (Marrocco and McClurkin, 1985).

CA release in response to the stationary and moving radial gratings are shown in Figure 4A. The stationary grating was ineffective in releasing CA. However, the rotating grating caused a concentration change of about $2 \mu \mathrm{M}$, with the same time course as that evoked by the strobe light. This response was so reliable that we used it routinely in all animals. These results suggest

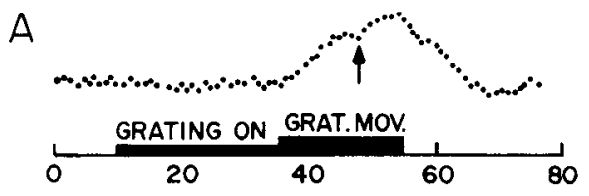

B
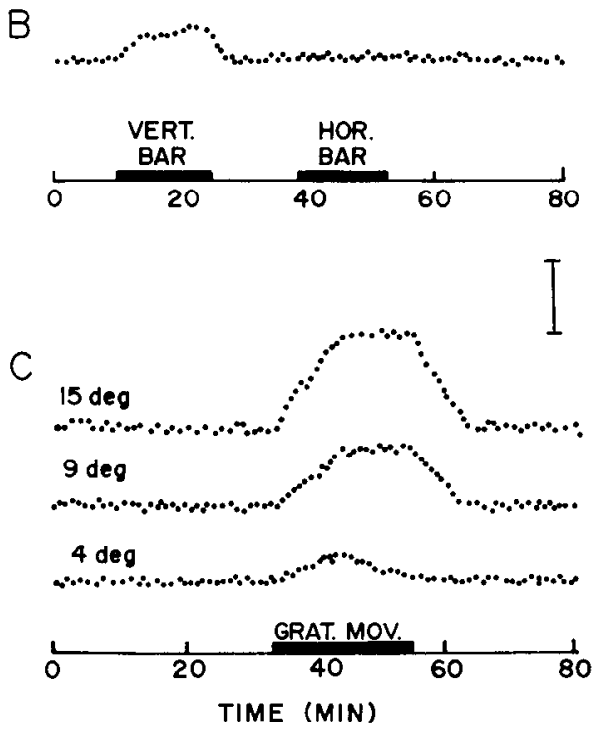

Figure 4. $A$, CA release in lamina IV of monkey $\mathrm{V} 1$ is evoked by a spinning but not a stationary radial grating stimulus. Grating diameter, $15^{\circ}$ arc, centered on the multiunit response field with central $5^{\circ}$ arc occluded. At arrow, occluder was removed, causing a further response increase. $B$, CA release evoked by a vertical, but not horizontal, oscillating light bar, centered on multiunit response field. Calibration bar $=$ $2 \mu \mathrm{M}$ change in CA concentration. $C$, CA release amplitude increases and response latency decreases with increasing diameter of radial grating. Monocular (right eye) stimulation.

that spatial and/or temporal changes were required for CA release. Precise visuotopic matching of stimulus and responding tissue appeared to be unnecessary, although this point clearly needs to be investigated further.

Figure $4 B$ shows an experiment designed to examine the effect of stimulus orientation on CA release. The multiunit receptive field was mapped as before with the microelectrode and the approximate orientation preference determined to be vertical. We then positioned a slit of light $\left(10^{\circ} \times 0.3^{\circ}\right)$ on the tangent screen and swept it back and forth across the response field over a distance of $5^{\circ}$ at about $20 \% \mathrm{sec}$. Virtually all of the release was obtained with vertical stimuli, and this suggested a sensitivity to orientation. We repeated this experiment in the V1 of 2 other animals. Horizontal and oblique orientations were preferred in these experiments, with no responses to orthogonal orientations.

Large and small unoriented stimuli are usually capable of driving subcortical neurons, while large stimuli of any orientation are generally ineffective for cortical neurons, especially those with end-stopped inhibition (Hubel and Wiesel, 1968). We used this fact to further our understanding of the stimulus requirements for release. We systematically varied the area of the radial grating. The multiunit response region for each eye was localized and rotating gratings of different areas centered on this region were presented (Fig. $4 \mathrm{C}$ ). Concentration changes appear proportional to stimulus area. However, the changes were driven only by the left eye, suggesting that stimuli much 

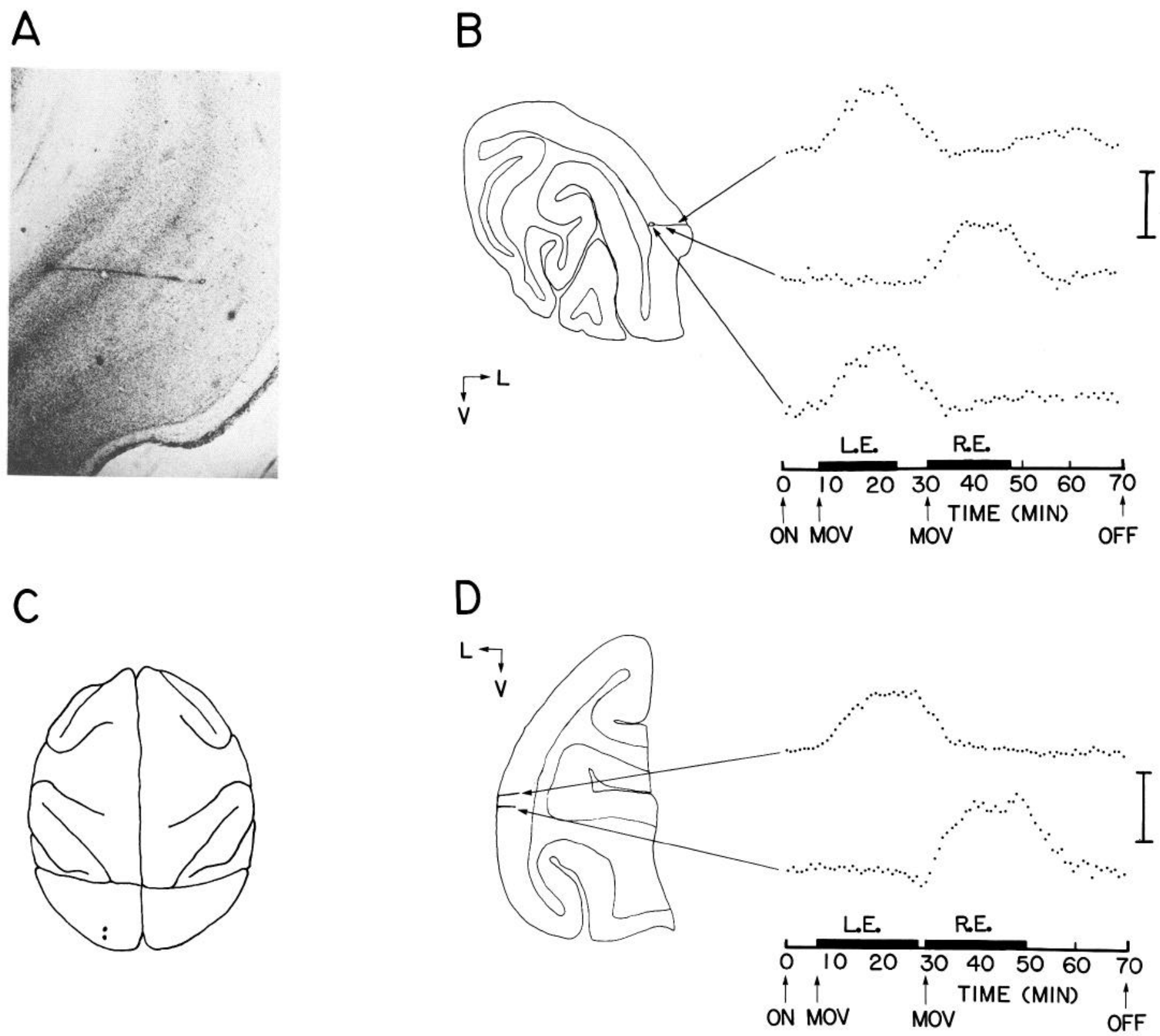

Figure 5. CA release varies with the physiological ocular dominance. $A$, Nissl-stained sagittal section showing tangential penetration of electrode array into monkey V1. Note that the electrode was tilted $10^{\circ}$ laterally from the plane of section. $B$, Outline of section in $A$ showing electrode track and CA response to spinning but not stationary radial grating at depths of $0.5,1.0$, and $1.5 \mathrm{~mm}$. See text for further details. $C$, dorsal view of monkey brain showing a pair of penetrations in the left hemisphere. $D$, Outline of parasagittal section from brain in $C$ showing electrode tracks and responses to spinning but not stationary radial gratings at two different locations. Tip of electrode was located $1.0 \mathrm{~mm}$ below the cortical surface in lamina IV in both penetrations. Calibration bars in $B$ and $D$ show $2 \mu \mathrm{M}$ change in CA concentration.

beyond the limit of the ocular dominance column did not contribute to the measured CA release.

Figure $4 A$ also shows the effect of stimulating different parts of the visual field on CA release. The central $4^{\circ}$ of a $9^{\circ}$ radial grating was occluded at the beginning of the radial motion. At the vertical arrow, the occluder was removed, and additional $\mathrm{CA}$ release was recorded. At face value, this result suggests that the response summated inputs across large areas of visual space. However, some of the increase was undoubtedly due to stray light falling in the center of the grating. The sensitivity of the release to small changes in stimulus luminance (see Fig. $3 A$ ) also supports this interpretation.
A similar dependence of the response on stimulus area was seen when drifting bars of light were used. A light bar $0.5^{\circ} \times$ $15^{\circ}$ evoked a response of about $0.8 \mu \mathrm{M}$, while a bar $3.0^{\circ} \times 15^{\circ}$ evoked a change in CA concentration of about $1.5 \mu \mathrm{M}$ (data not shown). In neither stimulus array do we know that stimulus area was the key parameter, since total luminous flux changed concurrently.

To summarize, the results of the strobe experiments support the idea that release depends on neurons whose receptive fields have few requirements for patterned stimulation. In contrast, the differential responses to oriented stimuli, and to a lesser extent the spinning radial grating, suggest a role for neurons 


\section{CAT}
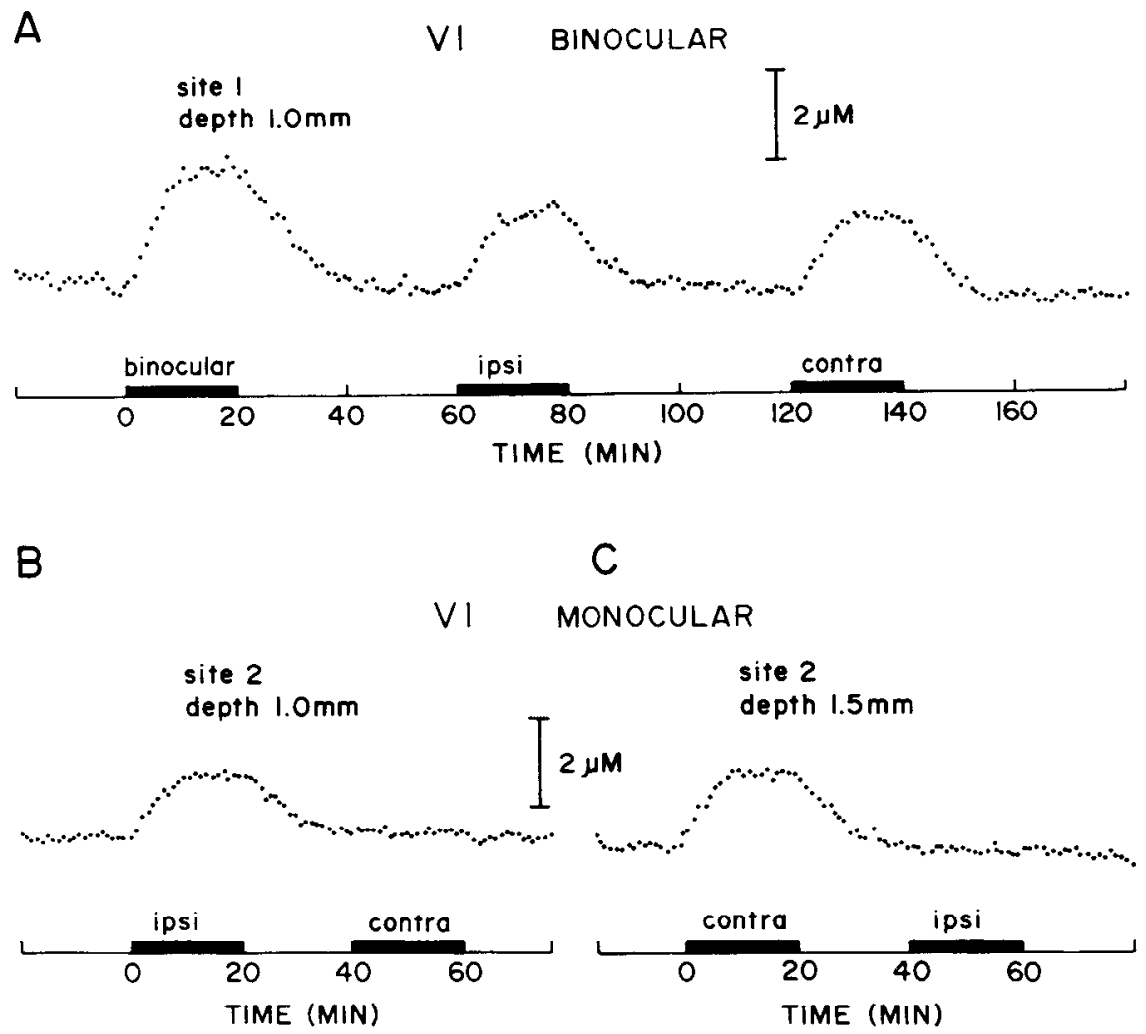

Figure 6. A, Binocular $\mathrm{CA}$ release elicited by strobe stimulus $(20 \mathrm{~Hz})$ recorded from lamina IV in a penetration normal to the surface of cat V1. Strobe intensity, 3.0 FtL. Note binocular summation of CA response. $B$ and $C$, monocular sites recorded at different depths of a tangential penetration through the medial bank of cat area V1. requiring highly patterned inputs. Pattern-sensitive responses would appear to rule out mechanisms based solely on LC activity. We conclude that $\mathrm{CA}$ release must be mediated in part by thalamic and/or cortical visual neurons.

\section{Ocular dominance of NE/DA release}

The above experiments suggest that neurons involved in CA release have some stimulus specificity requirements but provide little clue to the identity of the pathways in which the cells are located. In order to learn which pathway may be important, the combination electrode was introduced tangentially into the cortex and advanced slowly. Measurements of multiunit electrical activity were taken at $250 \mu \mathrm{m}$ intervals. At each depth we stimulated right and left eye receptive fields separately and judged the relative amounts of unit activity to be right dominant, left dominant, or cqual. Wc paused for about $10 \mathrm{~min}$ at each 500 $\mu \mathrm{m}$ interval to allow the brain tissue to adjust physically to the electrode array. We then switched to electrochemical recording and again stimulated each eye separately.

Figure 5 shows the results from one monkey. Figure $5 \mathrm{~A}$ shows the histologically reconstructed electrode penetration. At 0.5 $\mathrm{mm}$, electrical activity was dominated by the left eye; at 1.0 Imm, the activity was oblained only from the right eye; at 1.5 $\mathrm{mm}$, the dominant eye again became the left. The changes in $\mathrm{CA}$ concentration paralleled the changes in multiunit activity (Fig. $5 B$ ). It would thus appear that some release of CA into ECF occurs from neuronal processes within the ocular dominance column.

Figure $5 D$ shows another experiment from a second monkey in which the electrode array was lowered to a depth of $1.0 \mathrm{~mm}$, where multiunit activity was judged to be dominated by the left eye. Changes in $\mathrm{CA}$ concentration were evoked by stimulation of the left eye only. The array was then withdrawn, moved caudally by about $1 \mathrm{~mm}$ (see Fig. 5C), and lowered to a depth of $1 \mathrm{~mm}$. At this new site, the right eye drove the electrical activity and the CA release, presumably reflecting the electrode's entrance into a different cortical column.

Figure 6 shows 2 experiments on cat cortex in which the electrode was passed normally $(6 A)$ and tangentially $(6 B)$ through lamina 4 . We were able to drive electrical activity and cause CA release from both eyes at site 1 . Binocular stimulation shows about a $30 \%$ greater response than either eye alone. In Figure $6 B$, electrical activity and CA release were evoked by ipsilateral (left) eye stimulation only; advancing the electrode array by 500 $\mu \mathrm{m}$ shifted the ocular dominance and CA release to the contralateral (right) eye. Similar results have been obtained from 6 tangential penetrations in 3 other cats.

The results obtained for laminae 2 and 3 were similar to those shown for lamina 4. Although the magnitude of concentration changes was smaller for laminae 2 and 3, monocular as well as binocular sites were observed. We could not differentiate electrochemical measurements of release from laminae 1 or 5 because their widths were small compared with the electrode tip. No differences between cat and monkey V 1 cortical regions were noted.

The monocular sites are strong evidence for release sites dependent on LGN terminals or first-order cortical neurons. An independent way to test further the notion that $\mathrm{CA}$ release depends on specific sensory afferents is to exploit anatomical differences in geniculostriate projections between cats and monkeys. The afferents from the monkey LGN terminate in cortical area V1 but not in V2 (Hendrickson et al., 1978). Thus, if the 


\section{MONKEY}

A
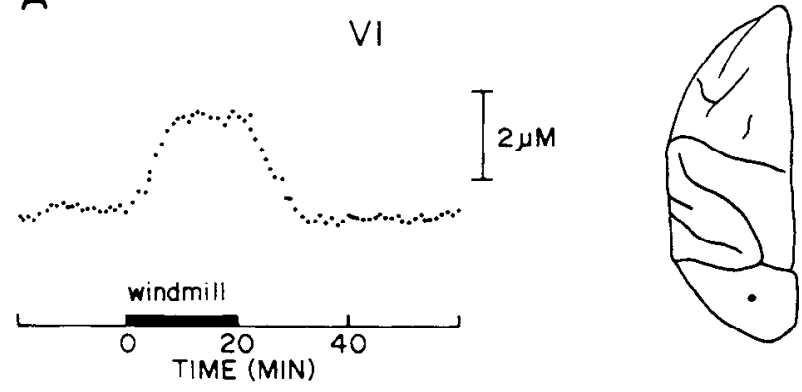

B
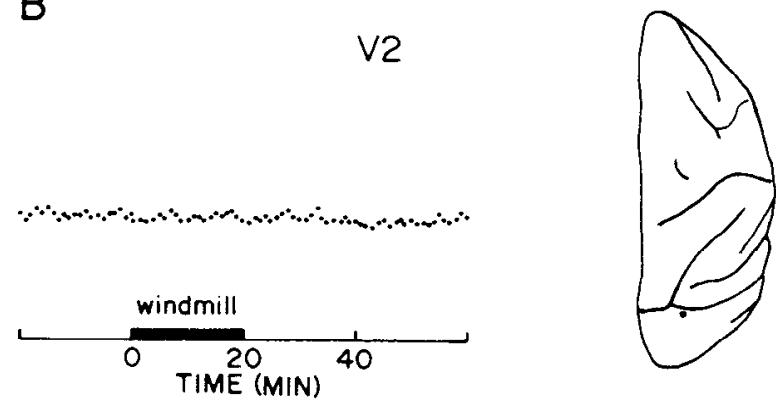

\section{CAT}

C

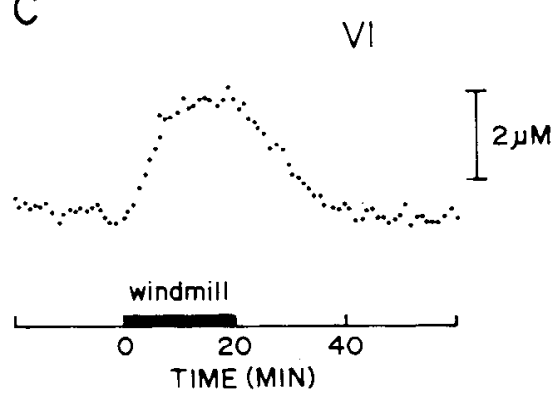

D

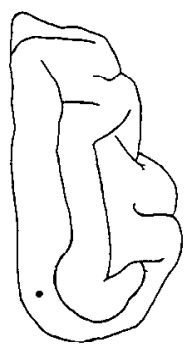

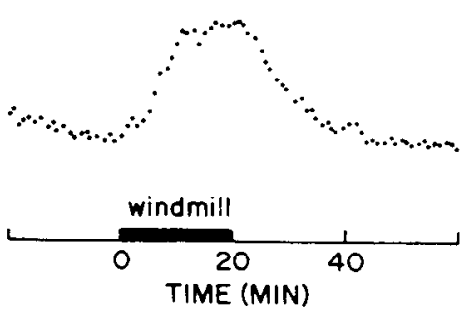

V2

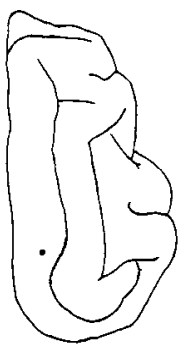

Figure 7. CA release in lamina IV to spinning windmill (radial grating) depends on the presence of LGN terminals. $A$ and $B$, CA release is evoked in monkey area V1 but not area V2. Sections to the right of responses show penetration locations (small dots). $C$ and $D$, CA-evoked release from lamina IV in cat area V1 and V2 under similar stimulus conditions. Binocular stimulation.

release is tied to thalamic afferents, then the innervation pattern predicts transmitter release in $\mathrm{V} 1$ but not $\mathrm{V} 2$. If release is observed in V2, then it is not dependent on the presence of LGN terminals. In contrast, the cat visual system contains LGN afferents that project to V1 and V2 (Stone and Dreher, 1972). Thus, rclease based upon action of thalamic afferents predicts visually evoked changes in concentration in both visual areas in cat. Figure 7 shows the results obtained from cat and monkey areas $\mathrm{V} 1$ and $\mathrm{V} 2$ by stimulating with the moving radial grating. Figure 7, $A$ and $B$, suggests that release is limited to the primary visual area in the monkey; Figure $7, C$ and $D$, suggests that release is obtained in primary and secondary visual areas of the cat. Each of these experiments has been replicated with essentially the same results for both areas of 2 other cats and a monkey. We conclude that LGN afferents must be present to record visual stimulus-evoked $\mathrm{CA}$ release in both cat and monkey cortices.

In summary, we have shown that the release is usually dominated by one eye or the other and that the electrode distances between eye dominance reversal are about the same as those reported for electrophysiological experiments. This suggests that the processes are monocular and appcar to climinatc predominantly binocular pulvinar efferents as the source of the CA release. The stimulus specificity (orientation effect, responses to radial grating) and the similarities in CA release patterns between cortical laminae are consistent with cortical neuron involvement. However, the CA release columns appear more consistent with an interpretation based on a dominant role for thalamic afferents. In the next section, we describe experiments to establish the anatomical, pharmacological, and physiological specificity of the response.

\section{Control experiments}

\section{Effects of blocking LC activity}

We have previously shown that selective inhibition of impulse traffic in rat DA/NE systems markedly reduces or abolishes electrochemical signals associated with release of both monoamines (Howard-Butcher et al., 1985; Lane and Blaha, 1986; Lane et al., 1986). Barbiturates appear to reduce LC activity transiently in rats and monkeys (Cedarbaum and Aghajanian, 1977; Engberg and Svensson, 1979; Foote et al., 1980; AstonJones and Bloom, 1981). We were thus able to use barbiturate injections as a test of the integrity of the electrode and surrounding tissues independent from visual stimulation. Sodium amobarbital (Surital, $10 \mathrm{mg} / \mathrm{kg}$, i.v.) was injected over a $5 \mathrm{sec}$ period and the CA release assessed for $40 \mathrm{~min}$. Figure 8 shows that transient declines in CA levels in the ECF were recorded in all areas sampled in the monkey brain, including those areasi.e., V2, V4, and somatosensory area 1 (SS1)-that failed to show increases following visual stimulation. In addition, Surital was observed both to reverse and to block the stimulus-evoked release of CA from V1 (not shown). In contrast, injections of equivalent volumes of normal saline, atropine, or dexamethasone produced no change in CA concentration. Identical CA release was seen in each of 3 monkeys tested. We conclude that the failure to release CA in monkey cortex was not due to a 
nonfunctional electrode or damaged cortical tissue but represented an inability of visual stimulation to cause CA release. Surital injections were not given to cats.

\section{Effects of visual stimulation on CA oxidation currents in other cortical areas}

While the visual response is clear, we have not provided evidence that the visual response is limited to visual areas. If, for example, the release is polysensory, then we should be able to record from SS1 and evoke CA release following visual stimulation.

Figure 9 presents results from recording sites in V1, V2, V4, and SS1 of monkey cortex. Results from V1 and V2 are similar to those of Figure 7 but recorded from cortical tissue representing different visual field locations. CA release was not obtained at the V4 electrode site in the anterior bank of the lunate sulcus following visual stimulation with the strobe light (Fig. $9 C$ ) or with the rotating radial grating (not shown). Similar negative findings were evident in area SS1 with strobe illumination or with tactile stimulation (skin taps, fur rubs, or vibratory stimuli). Recordings were not made from other areas in cat cortex.

The failure to record light-evoked CA release in V2, V4, and SS1, evident in both monkeys tested, is especially important because the endogenous tissue concentrations of CA in these areas are much higher than in V1 (Brown et al., 1979; Levitt et al., 1984). Coupled with the barbiturate study, the results lend strong support to the notion that CA release depends on a close interplay between visual subcortical afferents and LC terminals.

\section{Effects of chronic depletion of $N E / D A$}

Figure 10 shows the results of stimulating both eyes of one cat before (normal) and after the 6-OHDA pretreatment. No changes in the monitored baseline currents were observed for strobe or radial grating stimulation or any other stimuli presented. Tissue levels of NE and DA were found to be reduced by about $80 \%$ of their normal physiological values, within the range previously reported for 6-OHDA administration (Kasamatsu and Pettigrew, 1979; Daw et al., 1984; Trombley et al., 1986). Thus, our data suggest that oxidation currents were due to NE/DA only and that visually evoked release required NE/DA in amounts greater than $20 \%$ of the normal endogenous levels. These results are similar to those reported elsewhere for rat cortex (HowardButcher et al., 1985, 1986).

\section{Effects of visual stimulation on autonomic function}

It remains a possibility that some of the effects reported thus far have represented changes in general cortical arousal evoked by a noxious strobe stimulus, rather than specific responses involved in information processing.

To test these notions, we relied on the observations that during cortical arousal or REM sleep, the EEG becomes desynchronized, the heart rate increases, and the expired $\mathrm{CO}_{2}$ decreases due to an increased respiratory rate. In our paralyzed animal, however, we would expect expired $\mathrm{CO}_{2}$ to increase since respiratory rate is fixed.

We measured EEG, ECG, and $\mathrm{CO}_{2}$ levels before, during, and after the presentation of visual stimulation simultaneously with measurements of $\mathrm{CA}$ release. No changes were found in either the $\mathrm{ECG}$ or $\mathrm{CO}_{2}$ levels. While the EEG power spectra showed a great deal of variability within a stimulus condition, there was
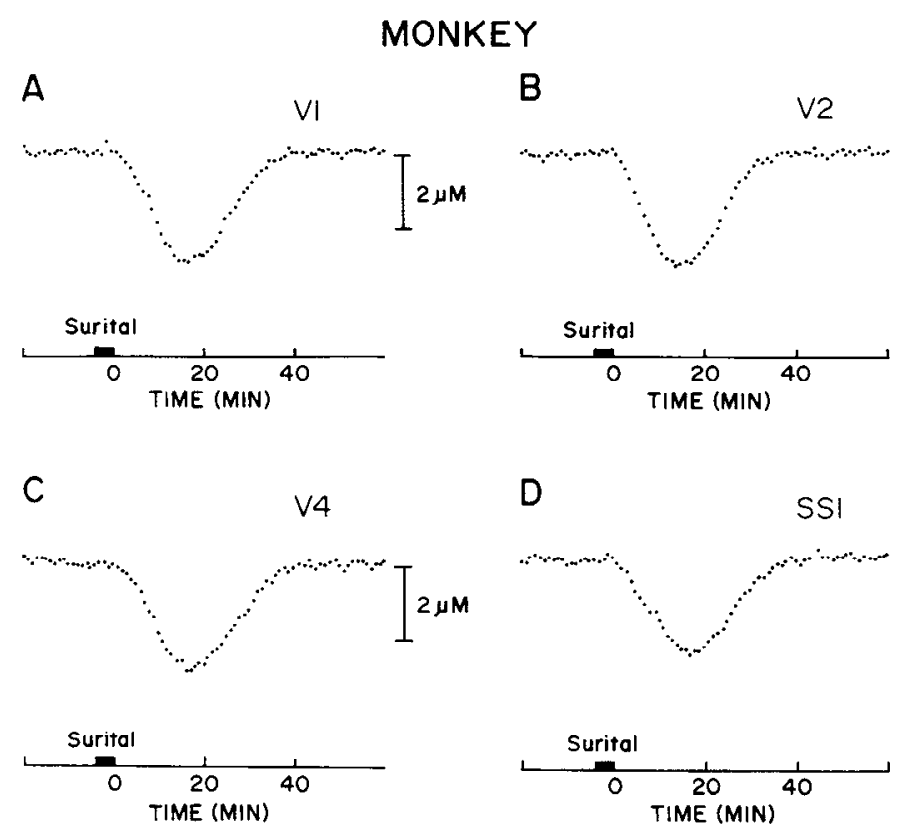

Figure 8. Intravenous Surital causes a decrease in extracellular CA concentration in monkey $\mathrm{V} 1(A), \mathrm{V} 2(B), \mathrm{V} 4(C)$, and SS1 $(D)$. No specific stimuli were present, but room lights were on. Binocular vision.

no obvious shift in state (Fig. $11, A-C$ ). In contrast, stimulation of the skin with a vibrator occasionally caused tachycardia but no release of CAs. These results suggest that the release of CAs into the ECF produced by visual or tactile stimulation is not accompanied in any systematic way by general arousal.

We also measured the change in EEG during the i.v. injections of Surital, as described above. In contrast to the lack of effects of visual stimulation, the barbiturate produced bradychardia, a dramatic reduction in the higher-frequency EEG components (Fig. $11, D-F$ ), and a decrease in the release of CA throughout the cortical ECF (see Fig. 8). Thus, production of states resembling slow-wave sleep (predominance of low-frequency waves) was accompanied by decreases in CA in cortical ECF.

\section{Discussion}

The main findings of this report are (1) that CA release in primate striate cortex in response to visual stimulation can be detected in vivo and (2) that there is an organization based on "CA release columns," akin to the physiological ocular dominance column.

In recent years, interest has grown in clcctrochcmical techniques that allow for the direct in vivo monitoring of monoamine neurotransmitter release in the brain (e.g., Adams and Marsden, 1982; Lane and Blaha, 1986). A problem with early work with these techniques was a lack of electrode specificity. However, with improvements in electrode specificity (Gerhardt et al., 1984), including the introduction of stereate-modified graphite-paste electrodes (Blaha and Lane, 1983), changes in the release of CAs can be monitored directly (Blaha and Lane, 1983, 1984; Gerhardt et al., 1984; Lane and Blaha, 1986). We have utilized these voltammetric methods in previous studies to monitor changes in DA and NE release following presentation of pharmacological and physiological stimuli to both anesthetized and freely moving rats. While the electrodes will not differentiate between NE and DA, we believe that the visual responses reported for the monkey cortex are due mostly to NE release. This 


\section{MONKEY}

A
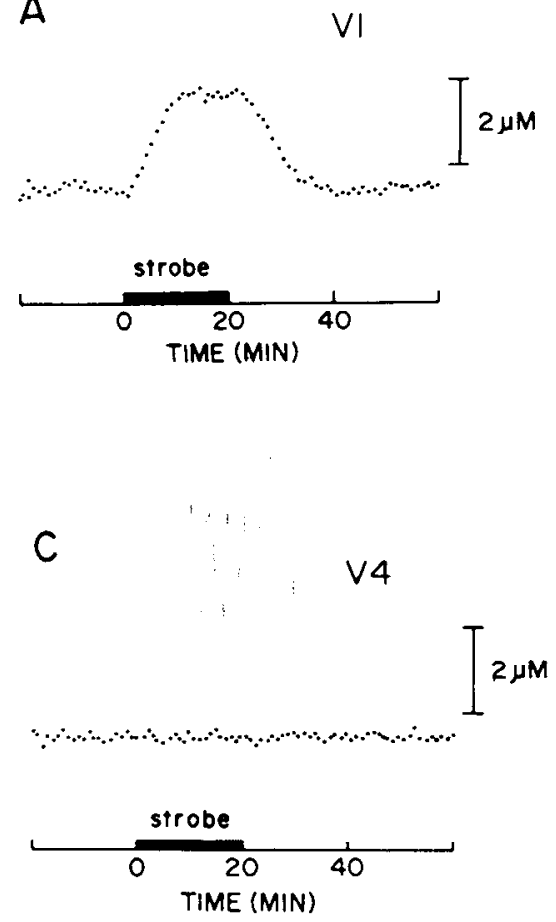

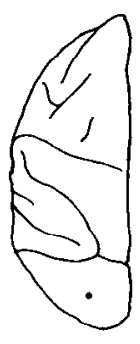

B
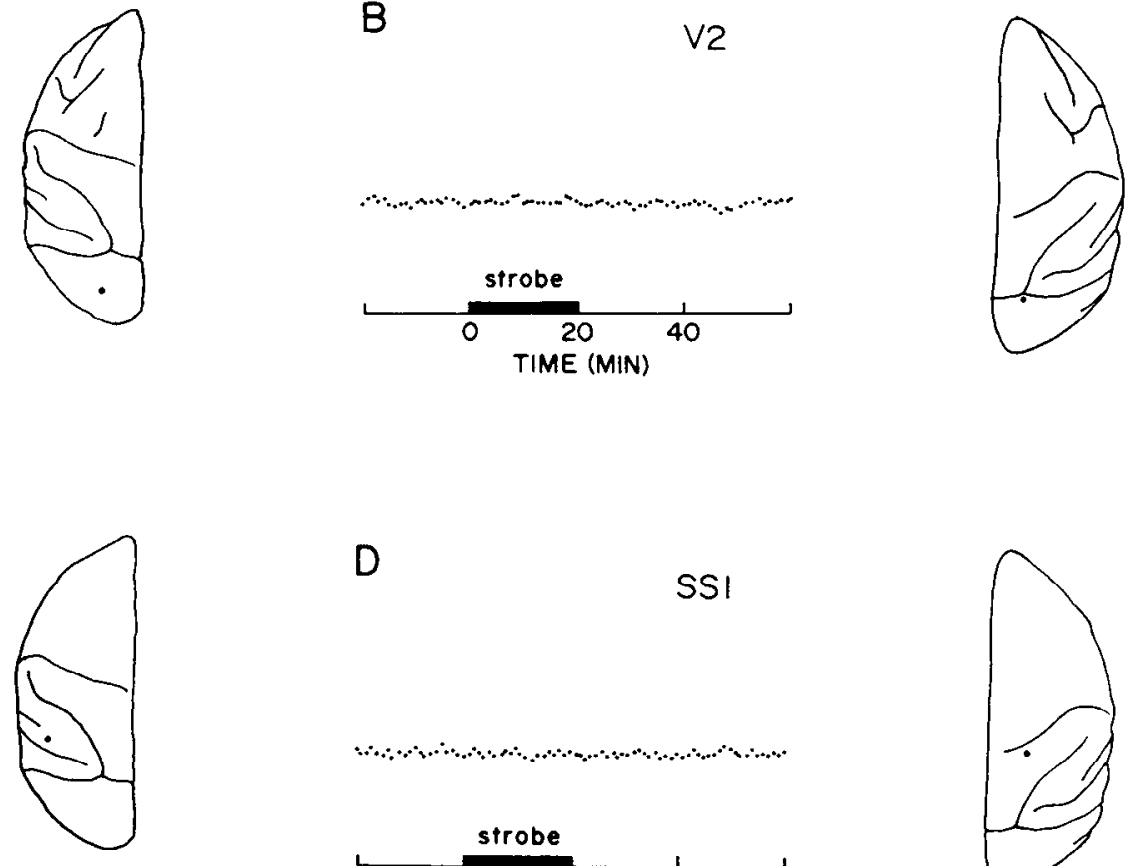

D

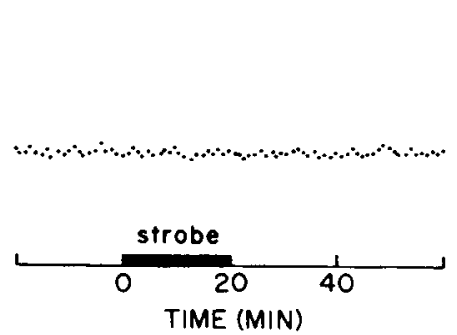

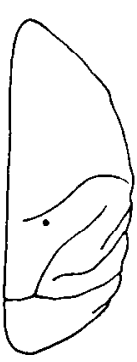

Figure 9. CA release in V1 to strobe stimulation $(10 \mathrm{~Hz})$ is not a manifestation of general visual cortical arousal. Stimulus evoked release is recorded in V1 $(A)$, but not V2 $(B)$, V4 $(C)$, or SS1 $(D)$. Other conventions as in Figure 7 . Strobe intensity, 2.0 FtL.

conclusion is based primarily on the predominance of NE over DA in the monkey occipital lobe (Brown et al., 1979). Thus, DA should have provided only a minor contribution to the signals seen here. Similarly, DA provides negligible interference to NE measurement in the rat cerebral cortex (Howard-Butcher et al., 1985, 1986). The situation is different for the cat. Since recent measurements of the tissue content of NE/DA were about
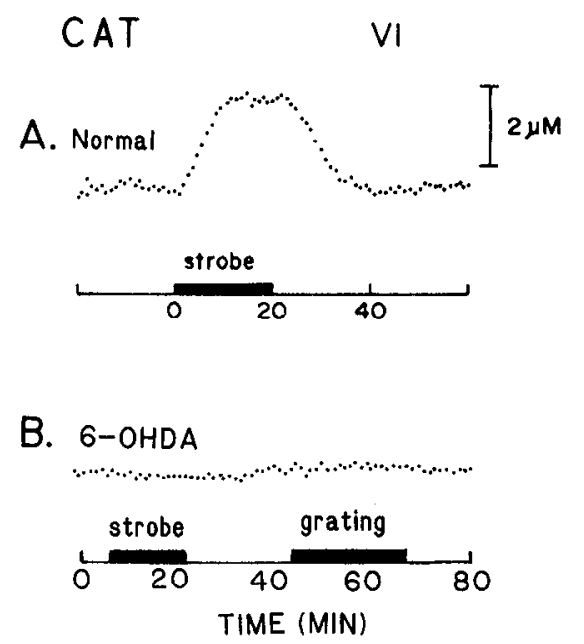

Figure 10. DA treatment abolishes CA release in cat $\mathrm{V} 1 . A, \mathrm{CA}$ release to strobe stimulus $(20 \mathrm{~Hz})$ from lamina IV of a normal adult cat. Intensity, 3.0 FtL. $B$. Lack of CA release to strobe or grating in area V1 of same cat following pretreatment with 6-OHDA. Binocular stimulation. See text for details.
50:20 (Trombley et al., 1986), we would expect that about $75 \%$ of the CA response in cat cortex would be due to oxidation of $\mathrm{NE}$ and about $25 \%$ to DA.

The second issue is the relationship of LC terminals with geniculocortical neurons. We have argued that the response specificity we observed makes it unlikely that LC neurons alone are responsible for NE/DA release. Moreover, while CA terminals appear to be preferentially localized in certain laminae, they do not appear to be vertically arranged in columnar patterns. However, immunohistochemical methods show that 5-HT terminals have only slight laminar preferences in sections cut normal to the cortical surface (e.g., Kossofsky et al., 1984). When viewed in sections cut tangentially to the surface, however, 5-HT appears to be preferentially localized between the areas labeled by cytochrome oxidase (interdol regions), suggesting a closer tie to ocular dominance columns (Hendrickson, 1984, 1985). Whether NE is similarly localized remains to be determined. Thus the sensory specificity of the LC system remains an open question.

Our failure to record CA release in monkey area V2 is difficult to reconcile with the anatomical demonstration that prestriate cortex is more densely innervated with CA terminals than striate cortex. Our data from cat show that $C A$ release is obtained from $\mathrm{V} 2$, but whether V2 is more densely innervated than V1 in cat is unknown. One possibility is that stimulus requirements for monkey V2 are more specific than those for cat V2. This is generally not likely, however, in view of current findings (e.g., Hubel and Wiesel, 1965; Baizer et al., 1977).

At the other end of the spectrum, sensory pathways alone cannot be responsible for increases in NE/DA levels since NE 


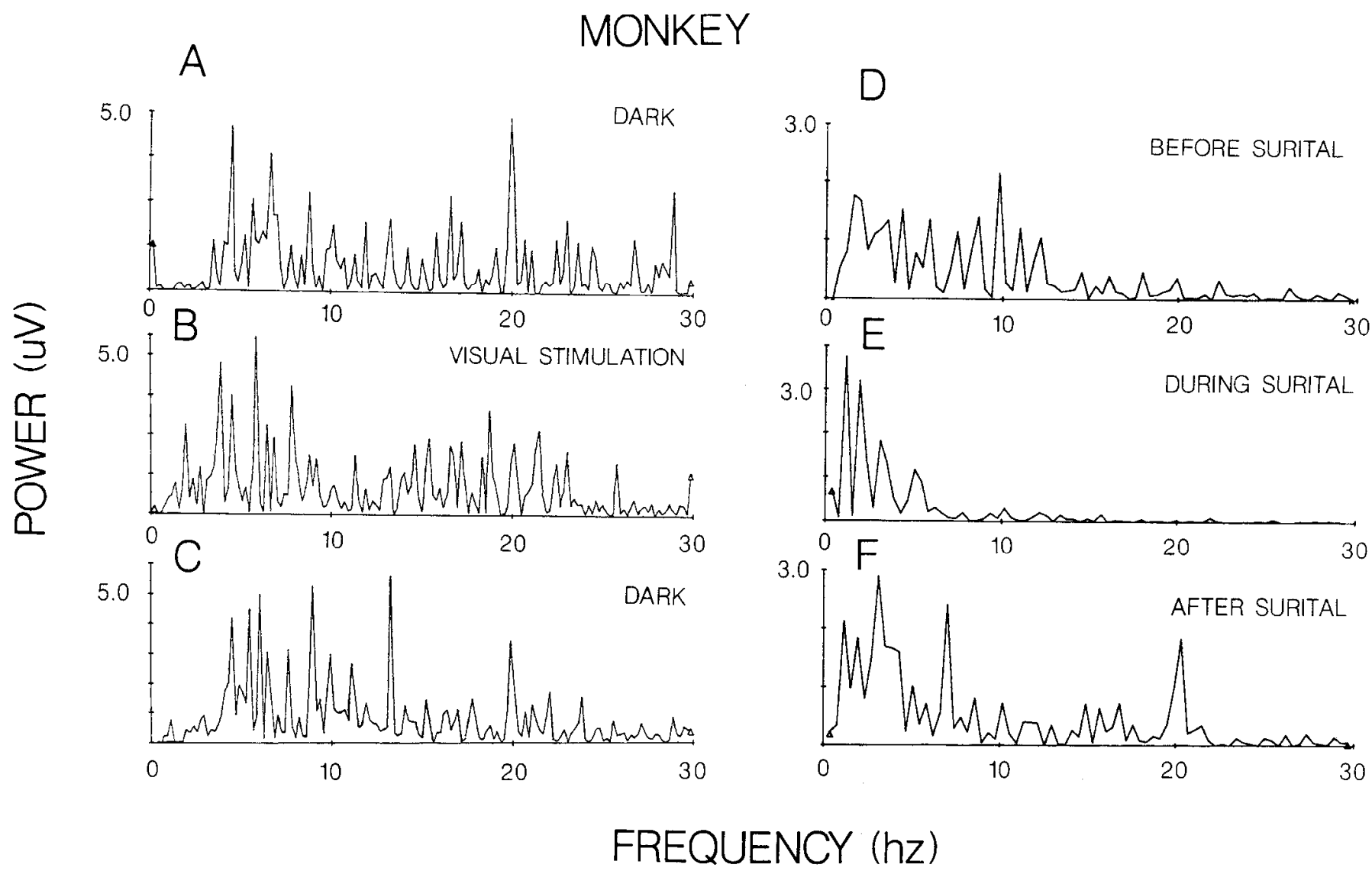

Figure 11. Specific EEG patterns recorded from monkey visual cortex are not associated with CA release. Power spectral analyses of EEG records obtained from electrodes placed symmetrically across visual cortices. $A$ and $C$, dark room, no visual input. $B$, stroboscopic illumination (20 $\mathrm{Hz}$ ); monkey 1. $D-F$, intravenous Surital causes a reduction in high frequency EEG components; monkey 2 . Bin width for $A-C(250 \mathrm{~ms})$ is half that of $D-F(500 \mathrm{~ms})$.

is not localized within thalamocortical afferents (e.g., Morrison and Foote, 1986) or cortical intrinsic neurons. Rather, it appears as though release must be due to an interaction between specific visual afferents and LC activity. Based on the differential responses to oriented stimuli and, to a lesser extent, the radial grating responses, our evidence points to the geniculostriate pathway as the critical sensory structure that interacts with LC activity. The nature of the interaction is certainly not clear, but gating of LC terminal release by geniculate terminals is one possible form that local control may take (e.g., Girault et al., 1984). The similarity in dimensions between "CA release columns" and the ocular dominance columns measured physiologically is consistent with this interpretation.

The results of the 6-OHDA experiment also argue in favor of a hypothesis based on local control by gating. That is, 6 OHDA abolishes the release of CA but does not alter the physiological ocular dominance pattern (unpublished observations; see also Kasamatsu and Pettigrew, 1979). In addition, stimulation of the LGN with implanted bipolar electrodes gave a robust field potential but caused no release of CA (unpublished observations). This suggests that joint activation of the pathway through the LGN and LC is necessary for CA release. However, the experiment in which the geniculostriate inputs are lesioned and $\mathrm{CA}$ release measured has yet to be performed.

In fact, it is difficult to localize the level(s) along the visual pathway at which the hypothetical interaction may occur. Consider the experiments demonstrating the orientation preferences of CA release. One cannot attribute the electrophysiological and electrochemical responses to oriented stimuli as occurring from the same orientation columns given the distance $(300 \mu \mathrm{m})$ separating the 2 electrode tips. However, given the observed correspondence between these 2 responses, it is not unlikely that identical electrophysiological changes to oriented stimuli are occurring within the immediate surround of the graphite electrode. There are also problems in attempting to use stimulus characteristics to match specific receptive field characteristics and thus preferentially activate cells at one anatomical site. For example, while stroboscopic stimulation is usually considered diffuse, it nonetheless activates neurons at many different levels, including cortical (see Olson and Pettigrew, 1974). Its use preferentially, but not exclusively, activates neurons with concentric receptive fields.

There is also one major argument against the gating version of the LC-LGN interaction hypothesis. If an LGN axon terminal is to gate release from LC terminals, then the latter ought to be found to be postsynaptic to the former. Available electron microscopic evidence suggests that many LC terminals, having dense core granules, make dendrodendritic synapses (e.g., Groves and Wilson, 1980; Itakura et al., 1981), but, to our knowledge, synapses onto LC terminals have not been reported. It is possible, however, that some form of neurochemical gating may exist in the absence of standard synaptic proximities.

Several laboratories have used electrochemical methods to study CA release in vivo (e.g., Adams and Marsden, 1982; Lane 
and Blaha, 1986). Direct comparisons between these previous studies and the present findings are not straightforward since most of the past work was performed with rodents. However, retinal illumination has been shown to release NE from LChippocampus grafts in oculo (Gerhardt et al., 1984). In addition, CAs can be released into ECF of rat cerebral cortex and other brain regions selectively by several types of physiological and pharmacological stimuli, e.g., potassium and neuroleptics (Blaha and Lane, 1983, 1984; Gerhardt et al., 1984; Rose et al., 1985; Howard-Butcher et al., 1985, 1986; Lane and Blaha, 1986). The changes in concentration found in these studies were very similar to those of the present findings. It has also been reported that treatment with the specific NE neurotoxin xylamine has been shown to block the release of NE from rat cerebral cortex (Howard-Butcher et al., 1985, 1986). Similarly, 6-OHDA destruction of the nigrostriatal projection markedly attenuated or abolished DA release produced by physiological stimuli (Blaha and Lane, 1984; Rose et al., 1985; Lane and Blaha, 1986).

\section{Functional significance of $C A$ release}

We find it unlikely that CA levels are simply related to the level of behavioral arousal or state of sleep. Interestingly, Vertes (1984) has recently concluded that the LC is not exclusively involved in the control of any phase of sleep. However, our conditions of anesthesia could have produced a dissociation of cortical EEG and CA release. Had we measured these effects in a behaving animal, different results might have been obtained.

NE has been implicated in several global behaviors, e.g., fear, eating, and attention (Foote et al., 1980; Mason, 1981; Bloom et al., 1986). The notion of enhancement of signal-to-noise ratios in sensory systems has received some attention (e.g., Sara, 1985; Bloom et al., 1986). In this sense it may be acting like a neuromodulator in controlling the overall responsiveness to synaptic inputs, even under conditions of constant behavioral arousal (c.g., scc rcvicw by Woodward et al., 1979). Vidcen ct al. (1984) have, in fact, reported that some cortical neurons suppressed by NE iontophoresis show increases in the ratio of evoked response to background firing. The NE system could achieve a control of signal-to-noise ratios in cortical modules by adjusting the responsiveness to visual signals of the input laminae (mainly layers 2 and 4 ) relative to the output laminae (layers 3, 5, and 6).

In an attempt to validate this hypothesis, we have recently asked whether the presence of CAs affects cortical evoked potentials to multiple strobe flashes (Marrocco et al., in preparation). Cats with normal CA levels show a slow, monotonic growth in the V1 primary component amplitude (see Arden et al., 1980) during the early phase of adaptation to the strobe. The changes are similar to the cortical augmenting responses reported by Bishop et al. (1961) and are thought to be due to nonspecific cortical activation via brain-stem pathways (but see Ferster and Lindstrom, 1985). Cats deprived of CAs show a much reduced growth curve with a longer time constant and lower amplitude. These results suggest that augmenting responses may be partly due to CA release from LC neurons and reflect increased signalto-noise ratios in sensory pathways.

\section{References}

Adams, R. N., and C. A. Marsden (1982) Electrochemical detection methods for monoamine measurements in vitro and in vivo. In Handbook of Pharmacology, Vol. 15, L. L. Iversen, S. S. Iversen, and S. H. Snyder, eds., pp. 1-74, Plenum, New York.
Adrien, J., G. Blanc, P. Buisseret, Y. Fregnac, E. Gary-Bobo, M. Imbert, J. P. Tassin, and Y. Trotter (1985) Noradrenaline and functional plasticity in kitten visual cortex: A re-examination. J. Physiol. (Lond.) 367: 73-98.

Arden, G. B., I. Bodis-Wollner, A. M. Halliday, A. Jeffreys, J. J. Kulikowski, H. Spekreijse, and D. Regan (1980) Methodology of Patterned Visual Stimulation. Brussels Symposium, Junk, Amsterdam.

Aston-Jones, G., and F. E. Bloom (1981) Norepinephrine-containing locus coeruleus neurons in behaving rats exhibit pronounced responses to nonnoxious environmental stimuli. J. Neurosci. 1: 887900

Baizer, J. S., D. L. Robinson, and B. M. Dow (1977) Visual responses of area 18 neurons in awake, behaving monkeys. J. Neurophysiol. 40: 1024-1037.

Bender, D. B. (1982) Receptive field properties of neurons in the macaque inferior pulvinar. J. Neurophysiol. 48: 1-17.

Bishop, G. H., M. H. Clare, and W. M. Landau (1961) The equivalence of recruiting and augmenting phenomena in the visual cortex of the cat. Electroencephologr. Clin. Neurophysiol. 13: 34-42.

Blaha, C. D., and R. F. Lane (1983) Chemically modified electrode for in vivo monitoring of brain catecholamines. Brain Res. Bull. 10: 861-864.

Blaha, C. D., and R. F. Lane (1984) Direct in vivo electrochemical monitoring of dopamine release in response to neuroleptic drugs. Eur. J. Pharmacol. 98: 113-117.

Bloom, F. E. (1975) The role of cyclic nucleotides in central synaptic function. Rev. Physiol. Biochem. Pharmacol. 76: 1-130.

Bloom, F. E., J. A. Schulman, and G. F. Koob (1986) In Handbook of Experimental Pharmacology, Vol. 2, U. Trendlenburg and N. Weiner, eds., Springer-Verlag, Berlin.

Brown, R. M., A. M. Crane, and P. S. Goldman (1979) Regional distribution of monoamines in the cerebral cortex and subcortical structures of the rhesus monkey: Concentrations and in vivo synthesis. Brain Res. 168: 133-150.

Cedarbaum, J. M., and G. K. Aghajanian (1977) Catecholamine receptors on locus coeruleus neurons: Pharmacological characteristics. Eur. J. Pharmacol. 44: 375-387.

Daw, N. W., T. W. Robertson, R. K. Rader, T. O. Videen, and C. J. Coscia (1984) Effect of lesions of the dorsal noradrenergic bundle on visual deprivation in the kitten striate cortex. J. Neurosci. 4: 1354 1360.

Engberg, G., and T. H. Svensson (1979) Amphetamine-induced inhibition of central noradrenergic neurons: A pharmacological analysis. Life Sci. 24: 2245-2254.

Ferster, D., and S. Lindstrom (1985) Augmenting responses evoked in area 17 of the cat by intracortical axon collaterals of corticogeniculate cells. J. Physiol. (Lond.) 367: 217-232.

Foote, S. L., G. Aston-Jones, and F. E. Bloom (1980) Impulse activity of locus coeruleus neurons in awake rats and monkeys is a function of sensory stimulation and arousal. Proc. Natl. Acad. Sci. USA 77: 3033-3037.

Gerhardt, G. A., A. F. Oke, G. Nagy, B. Moghaddam, and R. N. Adams (1984) Nafion-coated electrodes with high selectivity for CNS electrochemistry. Brain Res. 290: 390-395.

Girault, J. A., U. Spampinato, H. E. Savaki, J. Glowinski, and M. J. Besson (1984) In vivo release of newly synthesized ${ }^{3} \mathrm{H}-\mathrm{GABA}$ in the rat striatum: Dopaminergic regulation. Neurosci. Lett. (Suppl.) 18: $\mathrm{S} 197$

Groves, P. M., and C. J. Wilson (1980) Monoaminergic presynaptic axons and dendrites in rat locus coeruleus seen in reconstruction of serial sections. J. Comp. Neurol. 193: 853-862.

Hefti, F., and D. Felix (1983) Chronoamperometry in vivo: Does it interfere with spontaneous neuronal activity in the brain? J. Neurosci. Methods 7: 151-156.

Hendrickson, A. E. (1984) Immunocytochemical localization of serotonin and GABA in macaque striate cortex. Invest. Ophthalmol. Vis. Sci. 25: 165 .

Hendrickson, A. E. (1985) Dots, stripes and columns in monkey visual cortex. Trends Neurosci. 8: 406-410.

Hendrickson, A. E., J. R. Wilson, and M. P. Ogren (1978) The neuroanatomical organization of pathways between the dorsal lateral geniculate nucleus and visual cortex in Old World and New World primates. J. Comp. Neurol. 182: 123-136.

Howard-Butcher, S., C. D. Blaha, and R. F. Lane (1985) Differential effects of xylamine on extracellular concentrations of norepinephrine 
and dopamine in rat central nervous system: An in vivo electrochemical study. J. Pharmacol. Exp. Ther. 233: 58-63.

Howard-Butcher, S., C. D. Blaha, and R. F. Lane (1986) An analysis of the exchange diffusion model for norepinephrine release using in vivo voltammetry. Ann. NY Acad. Sci. 473: 329-331.

Hubel, D. H., and T. N. Wiesel (1965) Receptive fields and functional architecture in two non-striate areas (18 and 19) of the cat. J. Neurophysiol. $28: 229-289$.

Hubel, D. H., and T. N. Wiesel (1968) Receptive ficlds and functional architecture of monkey striate cortex. J. Physiol. (Lond.) 195: 215243.

Hubel, D. H., and T. N. Wiesel (1972) Laminar and columnar distribution of geniculocortical fibers in the macaque. J. Comp. Neurol. 146: 421-450.

Itakura, T., T. Kasamatsu, and J. D. Pettigrew (1981) Norepinephrinecontaining terminals in kitten visual cortex: Laminar distribution and ultrastructure. Neuroscience 6: 159-175.

Kasamatsu, T., and P. Heggelund (1982) Single cell responses in cat visual cortex to visual stimulation during iontophoresis of noradrenalin. Exp. Brain Res. 45: 317-32.7.

Kasamatsu, T., and J. D. Pettigrew (1979) Preservation of binocularity after monocular deprivation in the striate cortex of kittens treated with 6-hydroxydopamine. J. Comp. Neurol. 185: 139-162.

Kossofsky, B. E., M. E. Molliver, J. H. Morrison, and S. L. Foote (1984) The serotonin and norepinephrine innervation of primary visual cortex in the cynomolgus monkey (Macaca fascicularis). J. Neurosci. 4: $168-178$

Lane, R. F., and C. D. Blaha (1986) Electrochemistry in vivo: Application to CNS pharmacology. Ann. NY Acad. Sci. 473: 42-63.

Lane, R. F., A. T. Hubbard, and C. D. Blaha (1978) Brain dopaminergic neurons: In vivo electrochemical information concerning storage, metabolism and release processes. Bioelectrochem. Bioenerg. 5: 504-525.

Lane, R. F., A. T. Hubbard, and C. D. Blaha (1979) Application of semidifferential electroanalysis to studies of neurotransmitters in the central nervous system. J. Electroanal. Chem. 95: 117-122.

Lane, R. F., C. D. Blaha, and A. G. Phillips (1986) In vivo electrochemical analysis of cholecystokinin-induced inhibition of dopamine release in the nucleus accumbens. Brain Res. 397: 200-205.

Levitt, P., and R. Y. Moore (1978) Noradrenaline neuron innervation of the neocortex in the rat. Brain Res. 139: 219-231.

Levitt, P., P. Rakic, and P. Goldman-Rakic (1984) Region-specific distribution of catecholamine afferents in primate cerebral cortex: A fluorescence histochemical analysis. J. Comp. Neurol. 227: 23-36.

Livingstone, M. H., and D. H. Hubel (1984) Anatomy and physiology of a color system in the primate visual cortex. J. Neurosci. 4: 309356.

Marrocco, R. T., and J. W. McClurkin (1985) Evidence for spatial structure in the cortical input to the monkey LGN. Exp. Brain Res. 59: $50-56$.

Mason, S. T. (1981) Noradrenaline in the brain: Progress in theories of behavioral function. Prog. Neurobiol. 16: 263-303.

McClurkin, J. W. (1984) Receptive field structure, response properties, and functional organization of the monkey lateral and inferior pulvinar. $\mathrm{Ph}$.D. dissertation, University of Oregon, Eugene, OR.
McClurkin, J. W., and R. T. Marrocco (1984) Visual cortical input alters spatial tuning in monkey lateral geniculate nucleus cells. $\mathbf{J}$ Physiol. (Lond.) 348: 135-152.

McClurkin, J. W., C. D. Blaha, R. F. Lane, and R. T. Marrocco (1985) In vivo measurement of catecholamine release in primate visual and somatosensory cortex. Soc. Neurosci. Abstr. 11: 499.

Morrison, J. H., and S. L. Foote (1986) Noradrenergic and serotonergic innervation of cortical, thalamic, and tectal visual structures in old and ncw world monkeys. J. Comp. Ncurol. 243: 117-138.

Morrison, J. H., S. L. Foote, M. E. Molliver, F. E. Bloom, and H. G. W. Lidov (1982) Noradrenergic and serotonergic fibers innervate complementary layers in monkey primary visual cortex. Proc. Natl. Acad. Sci. USA 79: 2401-2405.

Olson, C. R., and J. D. Pettigrew (1974) Single units in visual cortex of kittens reared in stroboscopic illumination. Brain Res. 70: 189204.

Palkovits, M. (1979) Dopamine levels of individual brain regions: Biochemical aspects of DA distribution in the central nervous system. In The Neurobiology of Dopamine, A. S. Horn, J. Korf, and B. H. C. Westerink, eds., pp. 343-356, Academic, New York

Pocket, S. (1985) Dopamine changes the shape of action potentials in hippocampal pyramidal cells. Brain Res. 342: 386-390.

Rose, G., G. Gcrhardt, I. Stromberg, L. Olson, and B. Hoffer (1985) Monoamine release from dopamine-depleted rat caudate nucleus reinnervated by substantia nigra transplants: An in vivo electrochemical study. Brain Res. 341: 92-100.

Sara, S. J. (1985) The locus coeruleus and cognitive function: Attempts to relate noradrenergic enhancement of signal/noise in the brain to behavior. Physiol. Psychol. 13: 151-162.

Schenk, J. O., E. Miller, R. Gaddis, and R. N. Adams (1982) Homeostatic control of ascorbate concentration in CNS extracellular fluid. Brain Res. 253: 353-356.

Stone, J., and B. Dreher (1972) Projections of X- and Y-cells of the cat's lateral geniculate nucleus to areas 17 and 18 of visual cortex. J Neurophysiol. 36: 551-567.

Frombley, P., E. A. Allen, J. Soyke, C. D. Blaha, R. F. Lane, and B. Gordon (1986) Doses of 6-hydroxydopamine sufficient to deplete norepinephrine are not sufficient to decrease plasticity in the visual cortex. J. Neurosci. 6: 266-273.

Vertes, R. P. (1984) Brainstem control of the events of REM sleep. Prog. Neurobiol. 22: 241-288.

Videen, T. O., N. W. Daw, and R. K. Rader (1984) The effect of norepinephrine on visual cortical neurons in kittens and adult cats. J. Neurosci. 4: 1607-1617.

Weber, J. T., M. F. Huerta, J. H. Kaas, and J. K. Harting (1983) The projections of the lateral geniculate nucleus of the squirrel monkey: Studies of the interlaminar zones and the S layers. J. Comp. Neurol. 213: $135-152$

Wiesel, T. N., and D. H. Hubel (1966) Spatial and chromatic interactions in the lateral geniculate body of the rhesus monkey. J. Neurophysiol. 29: 1115-1156.

Woodward, D. J., H. Z. Moises, B. D. Waterhouse, B. J. Hoffer, and R. Freedman (1979) Modulatory actions of norepinephrine in the central nervous system. Fed. Proc. 38: 2109-2116. 